\title{
ANÁLISE DO IMPACTO DA VARIAÇÃO DE DEMANDA SOBRE O NÍVEL DE SERVIÇO LOGÍSTICO: UM ESTUDO DE CASO EM UMA INDÚSTRIA MULTINACIONAL DE COSMÉTICOS
}

Julio Maria de Souza (Instituto Federal de São Paulo) julio.m.souza@uol.com.br

Luiz Felipe Rocha dos Santos (Instituto Federal de São Paulo) luiz_feliperocha@hotmail.com

\section{Resumo}

A atual competividade existente no mercado, exige das organizações melhores formas de se destacarem diante das necessidades de seus clientes, contribuindo assim, para uma busca constante por melhorias em seus produtos e serviços. Dentre estes, destacam-se as operações logísticas por apresentarem impactos diretos no resultado do negócio, como a alta representatividade de custos e/ou a perda de receita oriunda de um baixo nível de serviço. Um bom planejamento logístico contribui para uma gestão mais organizada de toda a cadeia de suprimentos, o que permite à organização penetrar de maneira eficaz em novos mercados e consequentemente, aumentar os seus lucros.

O planejamento de demanda, normalmente é o elemento mais notável no que diz respeito as etapas de planejamento dentro de toda a cadeia de suprimentos de inúmeras empresas, requerindo estudos e investimentos sobre os modelos matemáticos e políticas adotadas para uma tomada de decisão eficiente.

Este trabalho visa apresentar quais são os impactos no nível de serviço logístico através de uma avaliação das principais causas que contribuem para o aumento do índice de nãoatendimento, oriundas da variação de demanda em uma indústria multinacional de cosméticos.

Palavras-Chaves: Competitividade; Planejamento de Demanda; Nível de Serviço; Cadeia de Suprimentos; Planejamento Logístico

\section{Introdução}

De acordo com Ballou (2006), a logística é a essência do comércio, ela contribui decisivamente para melhorar o padrão econômico de vida geral. Quanto à empresa isolada operando numa economia de alto nível, a gestão eficaz das atividades logísticas é vital. Os 
mercados são muitas vezes de âmbito nacional ou internacional, mesmo que a produção se concentre em pontos relativamente escassos. A partir daí, surge uma preocupação mais intensa com o setor logístico e os seus impactos por parte das organizações, caracterizando o nascimento da área de logística nas empresas.

A logística empresarial, segundo as normas do Council of Logistics Management (CLM) é definida como o processo de planejamento, implantação e controle do fluxo eficiente e eficaz de mercadorias, serviços e das informações relativas desde o ponto de origem até o ponto de consumo com o propósito de atender às exigências dos clientes. No entanto, a definição acarreta que a logística é parte da cadeia de suprimentos (do inglês, supply chain), cuja essência baseia-se no gerenciamento integrado das diversas áreas e atividades que impactam a disponibilização de produtos.

Para Ballou (2006) as atividades a serem gerenciadas que compõem a logística empresarial variam de acordo com as empresas, dependendo, entre outros fatores, da estrutura organizacional, das diferentes conceituações dos respectivos gerentes sobre os que constitui a cadeia de suprimentos nesse negócio e da importância das atividades específicas para as suas operações.

A complexidade das decisões sobre a cadeia de suprimentos gera inúmeras possibilidades no que diz respeito a melhorias de processos para a otimização o planejamento logístico como um todo e consequentemente, a geração de destaque para a companhia, instigando ainda mais o aumento da competitividade existente no mercado.

No que diz respeito ao planejamento, temos diversas etapas que são de extrema importância para o desempenho do todo. Entretanto, normalmente, define-se como "ponto de início" o planejamento de demanda, que influencia diretamente nas demais partes e determina todo planejamento e capacitação logística, refletindo em custos através de turnos contratados, investimentos em maquinários, inovações e tecnologias, turnos e mãos de obras extras, entre outros aspectos fundamentais.

\subsection{Problema de Pesquisa}

Sabendo que a eficiência logística das organizações é um fator crítico de sucesso para o negócio perante a concorrência, é fundamental a compreensão de qual a melhor estratégia a ser adotada em relação a variação de demanda, visto que o atendimento ao maior número de clientes possíveis é essencial para o êxito da organização. Com base nisso, a pesquisa realizada neste trabalho visa encontrar através de uma análise quantitativa, a resposta para a 
seguinte questão: Diante da atual competitividade de mercado, a existência de variações na previsão de demanda (versus o real vendido) influência no atendimento ao cliente e consequente, no nível de serviço da organização?

\subsection{Objetivo da pesquisa}

O objetivo principal da pesquisa realizada neste trabalho é verificar quais são as principais causas ofensoras ao nível de serviço logístico da empresa estudada, diante das variações de demanda em um determinado período, a fim de se compreender em quais pontos da cadeia de suprimentos, devem ser realizadas ações corretivas ou investimentos para maior ganho de flexibilidade no atendimento. Já o objetivo secundário, baseia-se em propor, com base nas boas práticas de mercado, tratativas para os motivos identificados e ser utilizadas como base para tomada de decisões.

\subsection{Justificativa da pesquisa}

O tema proposto para este trabalho foi escolhido por ser considerado de grande relevância e importância para o desempenho das organizações e de um modo geral, para a economia, ambos em escala mundial.

Além disso, o autor busca aprofundar os seus conhecimentos sobre o tema, visto que este, está dentro do seu contexto profissional e contribuir de forma significativa para os estudos já existentes e para outros interessados em dar continuidade na pesquisa.

\section{Revisão de literatura}

Em “As aventuras de Alice no País das Maravilhas", Alice pergunta ao Gato Cheshire: "Você, por favor, poderia me dizer para onde devo ir a partir daqui?" E o gato lhe responde: "Isso depende principalmente de até onde você pretende chegar" (CARROL, 1983). O desempenho (Objetivo em matéria de lucros, crescimento e participação) das organizações no mercado, dependem prioritariamente da orientação estratégica que estas adotam como refencial. Para atingir seus objetivos da melhor maneira possível, as empresas elaboram um plano estratégico contendo todas as diretrizes necessárias. Este plano serve como base para que cada departamento consiga se planejar e contribuir com as entregas exigidas, ou seja a estratégia corporativa impulsiona as estratégias funcionais por estarem englobadas na primeira, conforme vemos a seguir: 
Figura 1 - Visão geral do planejamento estratégico funcional para um planejamento estratégico corporativo

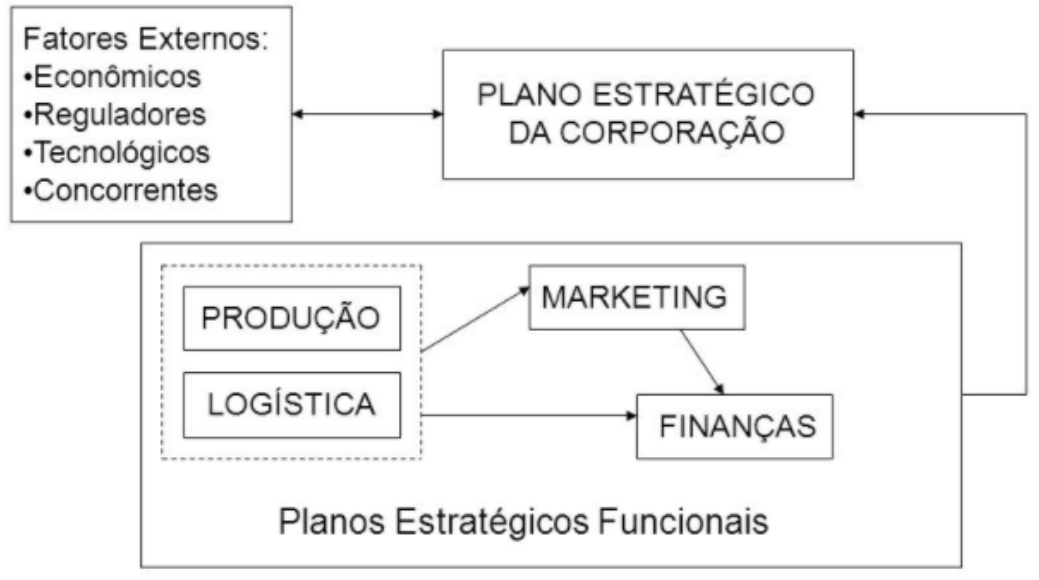

Fonte: Adaptado de International Journal of Physical DIstribution and Materials Management (1985)

De acordo com Ballou (2006), a estratégia corporativa é concretizada à medida que produção, marketing, finanças e logística dão continuidade aos planos elaborados para cumpri-la. Quando a StarKIst Foods optou pela estratégia baseada no suprimento, o marketing e a logística corresponderam com os respectivos planos para controlar os potenciais excessos de estoques daí resultantes. Esses planos incluíam promoções tipo "liquida atum" sempre que surgisse a necessidade de reduzir estoques. É uma promoção de resultados garantidos porque o atum, para os consumidores, nunca é demais, tanto que aproveitam ofertas como essa para estocá-lo.

No que diz respeito ao planejamento logístico a opinião é mais ou menos a mesma para qualquer organização, resumindo-se em três principais objetivos: melhoria de serviços, redução de custos e redução de capital.

As estratégias de melhoria de serviços estão completamente relacionadas com a política do nível de serviços logísticos adotada e os lucros esperados. Embora essas melhorias gerem um aumento de custos, os lucros são igualmente ampliados, podendo ser superiores. Como forma de se medir o desempenho da estratégia de serviços empregada, levam-se sempre em consideração os serviços proporcionados pela concorrência.

As estratégias para redução de custos baseiam-se, basicamente, no enxugamento dos custos variáveis referentes a armazenagem e ao transporte. Ou seja, está implicitamente correlacionada as decisões tomadas sobre as operações - neste ponto, são inúmeras as oportunidades que variam muito com o perfil e porte de cada empresa (BALLOU, 2006).

As estratégias para redução do capital são voltadas para a diminuir a necessidade aplicações financeiros, como por exemplo, investimentos de forma que, os retornos sejam maximizados. 
Para o alcance deste objetivo, são adotadas medidas de boas práticas, como por exemplo, negociações com fornecedores sobre prazos de pagamentos e geração de estoques.

Estes três objetivos são comuns aos três níveis de planejamento (Estratégico, tático e operacional), diferenciando-se em relação ao período para qual cada um destes está direcionado. Basicamente, o planejamento estratégico é considerado de longo prazo, com horizonte temporal de mais de um ano. O planejamento tático tem um horizonte temporal intermediário, normalmente inferior a um ano e por fim, o planejamento operacional é o processo decisório de curto prazo, com decisões normalmente tomadas a cada hora, ou diariamente (BALLOU, 2006).

Para cada nível, temos diferentes tipos de decisões, como podemos ver a seguir:

Figura 2 - Exemplos de processo de decisão estratégica, tática e operacional

\begin{tabular}{|c|c|c|c|}
\hline \multirow[b]{2}{*}{ Área da decisẫo } & \multicolumn{3}{|c|}{ Nivel da decisão } \\
\hline & Estratégica & Tática & Operacional \\
\hline Localização das instalaçōes & $\begin{array}{l}\text { Quantidade, área e localização } \\
\text { de armazéns, plantas a } \\
\text { terminais }\end{array}$ & & \\
\hline Estoques & $\begin{array}{l}\text { Localização de estoquese } \\
\text { normas de controle }\end{array}$ & $\begin{array}{l}\text { Níveis dos estoques de } \\
\text { segurança }\end{array}$ & $\begin{array}{l}\text { Quantidades e momento } \\
\text { de reposição }\end{array}$ \\
\hline Transporte & Seleção de modal & $\begin{array}{l}\text { Leasing de equipamento } \\
\text { periódico }\end{array}$ & Roteamento, despacho \\
\hline Processamento de pedidos & $\begin{array}{l}\text { Projeto do sistema de } \\
\text { entrada, transmissão de } \\
\text { pedidos e processamento }\end{array}$ & ser & $\begin{array}{l}\text { Processamento de pedidos, } \\
\text { atendimento de pedidos } \\
\text { pendentes }\end{array}$ \\
\hline Serviço aos clientes & Padrōes de procedimentos & $\begin{array}{l}\text { Regras de priorização dos } \\
\text { pedidos de clientes }\end{array}$ & Preparaçāo das remessas \\
\hline Armazenagem & $\begin{array}{l}\text { Seleção do material de } \\
\text { deslocamento, leiautic da } \\
\text { instalaçắo }\end{array}$ & $\begin{array}{c}\text { Escolhas de espaços sazonais e } \\
\text { utilizaçăo de espaços privados }\end{array}$ & $\begin{array}{l}\text { Separação de pedidos e } \\
\text { reposição de estoques }\end{array}$ \\
\hline Compra & $\begin{array}{l}\text { Desenvolvimento de relaçôes } \\
\text { fornecedor-comprador }\end{array}$ & $\begin{array}{l}\text { Contratação, seleçăo de } \\
\text { fornecedores, compras } \\
\text { antecipadas }\end{array}$ & $\begin{array}{l}\text { Liberaçã̃o de pedidos e } \\
\text { apressar compras }\end{array}$ \\
\hline
\end{tabular}

Fonte: Adaptado de Ballou (2006)

Padronizadamente, o planejamento logístico é realizado com base em tomadas de decisões, que por sua vez, se sustentam em quatro grandes pilares, são eles:

- O nível de serviço logístico determinado ao cliente

- As decisões sobre a localização das instalações

- As decisões sobre transportes

- As decisões sobre estoques

Os três tipos de decisões devem corresponder ao nível de serviço determinado pelo planejamento estratégico, atuando de forma interligada, como se os quatro pilares fossem uma unicidade decisória. 
Figura 3 - Pilar de decisões para o planejamento logístico

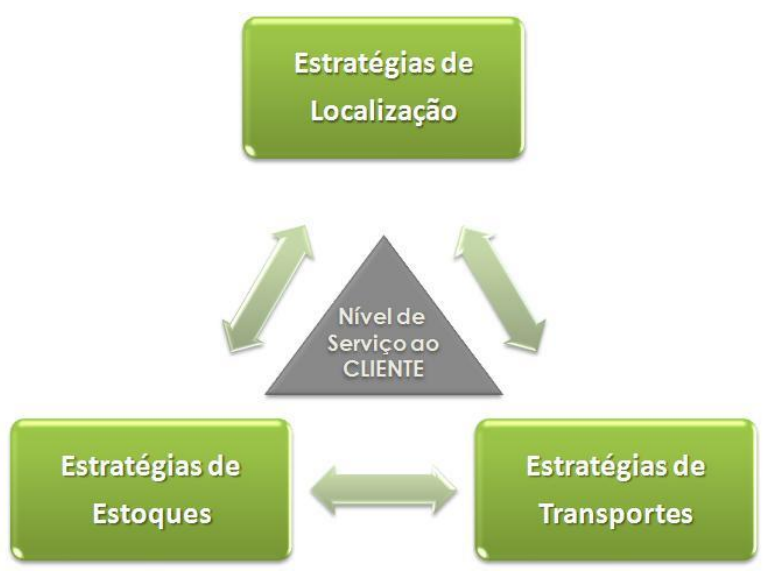

Fonte: Ballou (2006)

\subsection{Nível de serviço logístico}

De acordo com Christopher (1997), a logística é o processo de gerenciar, estrategicamente, a aquisição, movimentação e armazenagem de materiais (e os fluxos de informações correlatas) por meio da organização e seus canais de marketing, de modo a poder maximizar as lucratividades, presente e futura através do atendimento dos pedidos a baixo custo.

Segundo Bender (1997) para aperfeiçoar o sucesso da cadeia de suprimentos, é necessário que as empresas desenvolvam uma organização logística global, que utilize sistemas de gerenciamento que assegurem a efetiva operação de todas as atividades logísticas. De um modo geral, dentro do contexto existente a respeito do planejamento logístico existem muitos processos que conectam a empresa a seus fornecedores e clientes, visando sempre à satisfação do cliente, que por sua vez é administrado através do nível de serviço oferecido pela organização. Em essência o nível de serviço é o atendimento das especificações e necessidades definidas pelos clientes, com um objetivo preestabelecido de gerar valor para estes (FARIA \& COSTA, 2008).

O serviço ao cliente é descrito pelos especialistas Kyj e Kyj (1994) da seguinte forma: “... serviço ao cliente, quando utilizados de forma eficaz, constitui uma variável de capital importância que pode ter impacto significativo na criação de demanda e na manutenção da fidelidade do cliente". 


\section{Metodologia}

Este capítulo descreve as características principais da empresa estudada, retoma a apresentação do problema e na sequência, descreve os métodos de análise e resultados obtidos.

\subsection{Caracterização da empresa de estudo}

A empresa objeto de estudo deste trabalho é uma fabricante de produtos de beleza com sede no Brasil e presença em diversos países da América Latina e Europa.

Um grande dos grandes destaques da companhia é a estrutura tecnológica que ela possui em suas plantas produtivas e centros de distribuição, que contribui para a eficiência de seus processos e operações. Esses feitos, faz com que a empresa seja referência em benchmarkings com outras grandes do mercado.

Ao longo dos anos, a organização tem sido reconhecida pelo alto grau de inovação de seus produtos e pelo aprimoramento e valorização da prática de relacionamento - a chamada venda por relacionamento, tendo como objetivo aumentar a confiabilidade e a proximidade entre revendedor e cliente, além do compromisso com o desenvolvimento sustentável, através da relação da natureza com o homem.

Atualmente, a empresa conta com mais de 1,9 milhões de consultoras que de forma autônoma e não exclusiva, compram e revendem seus produtos. Por isso, é considerada uma das maiores empresas do mundo que atuam com o modelo de vendas.

A competitividade do mercado atual tem feito as empresas se preocuparem cada vez mais com diversos aspectos que possam render uma participação maior frente aos seus concorrentes. Entre esses aspectos, destaca-se a qualidade em relação ao seu atendimento. Por isso, nasce uma crescente preocupação em gerenciar o seu nível de serviço.

A empresa estudada, possui um modelo de vendas caracterizado como "venda direta", o qual o cliente compra da empresa os produtos que desejar e os revende ao consumidor final, com um ganho de $30 \%$ sobre o valor da venda.

Para realizar os seus pedidos, o cliente deve acessar o site de captação de pedidos, logar com o seu perfil e indicar quais são os produtos e as suas respectivas quantidades, pelo código de venda atrelado a ele.

No caso, do cliente tentar realizar uma compra e não conseguir por indisponibilidade de estoque, é sinalizado sistemicamente um corte de venda. Esse corte é utilizado como input do indicador que mede o desempenho da empresa em relação do nível de serviço. 
O indicador é chamado de Índice de Não Atendimento (INA) e permite mensurar o nível de indisponibilidade de produtos para atendimento dos pedidos através do site de captação e é calculado da seguinte forma:

$$
I N A=\frac{\sum \text { Cortes }}{\left(\sum \text { Cortes }+\sum \text { Captados }\right)}
$$

Onde:

- $\quad$ Cortes: Volume de itens indisponíveis no momento da captação do pedido.

- $\quad$ Captação: Volume de itens captados no pedido.

A figura a seguir nos traz um exemplo prático de como o INA é calculado:

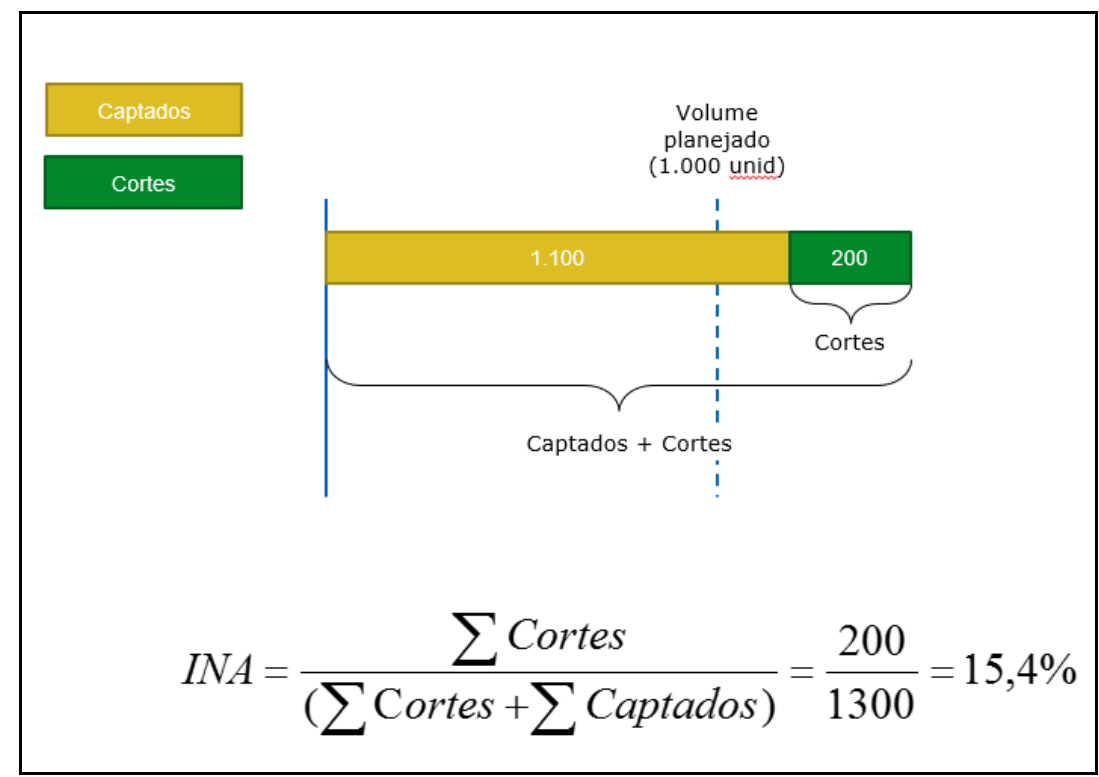

Figura 4 - Exemplo de cálculo do INA

Fonte: os autores

É importante frisar que a perda da venda é representada pela intenção de compra, ou seja, o total que a empresa poderia vender. Por isso, a somatória dos cortes está presente no denominador da equação.

Para cada corte computado, existe uma justificativa referente a indisponibilidade do produto. O pessoal responsável pelas operações, planejamento de produção, logística, comercial, tecnologia da informação, entre outros setores, devem justificar o motivo e o submotivo pelo qual o cliente não está conseguindo realizar a compra. Existem diversos motivos e submotivos pelo qual o produto é cortado e estão presentes em uma lista definida pela equipe que faz a 
medição do INA. Os gestores responsáveis pelas equipes que trabalham nas áreas correspondentes apontadas nas justificativas, deveriam se basear no que foi definido para encontrar oportunidades de melhorias nos processos e ganhos de produtividade para que os cortes não voltem a acontecer pelos mesmos motivos. Entretanto, na maioria das vezes, a atenção é focada para aqueles itens que estão "cortando" no dia, sem se trabalhar nas causas de maiores ocorrências, permitindo que estas voltem a acontecer.

Os motivos e submotivos definidos pela equipe responsável pelo INA, são apresentados na tabela a seguir:

Tabela 1 - Justificativas de cortes de vendas

\begin{tabular}{|c|c|}
\hline Motivo & Submotivo \\
\hline Carregamento de demanda & Erro na carga do plano \\
\hline Disponibilização de lançamentos & $\begin{array}{l}\text { Falha no planejamento de lançamento } \\
\text { Erro de projeto }\end{array}$ \\
\hline Disponibilização de produtos & $\begin{array}{l}\text { Atraso na entrega de terceiristas } \\
\text { Atraso na entrega de material de embalagem } \\
\text { Atraso na entrega de matéria prima } \\
\text { Atraso na entrega da fábrica } \\
\text { Atraso no recebimento - Operação Interna } \\
\text { Qualidade do insumo - Reprovação no recebimento } \\
\text { Qualidade do insumo - Reprovação na linha de produção } \\
\text { Liberação Alfandegária } \\
\text { Qualidade do Produto Acabado - Terceiro } \\
\text { Qualidade do Produto Acabado - Fábrica }\end{array}$ \\
\hline Distribuição de estoques & $\begin{array}{l}\text { Ajuste de inventário } \\
\text { Atraso no trânsito } \\
\text { Falha de planejamento de distribuição } \\
\text { Gargalo no envio } \\
\text { Gagalo no recebimento do CD } \\
\text { Trânsito indevido (Carga não existente) }\end{array}$ \\
\hline Falha nos sistemas & $\begin{array}{l}\text { Problemas de sistema } \\
\text { Erro de cadastro }\end{array}$ \\
\hline Planejamento de produção & $\begin{array}{l}\text { Atendimento LATAM } \\
\text { Descontinuação } \\
\text { Falha no planejamento de insumos } \\
\text { Falha no planejamento de produto acabado } \\
\text { Priorização por superação }\end{array}$ \\
\hline Superação de Vendas & $\begin{array}{l}\text { Atraso na entrega de terceiristas } \\
\text { Atraso na entrega de material de embalagem } \\
\text { Atraso na entrega de matéria prima } \\
\text { Atraso na entrega da fábrica } \\
\text { Balanceamento entre CDs } \\
\text { Atraso na distribuição } \\
\text { Lead time de distribuição } \\
\text { Lead time de produção e distribuição } \\
\text { Lead time da cadeia de abastecimento - ME } \\
\text { Lead time da cadeia de abastecimento - MP } \\
\text { Lead time da cadeia de abastecimento - PA }\end{array}$ \\
\hline
\end{tabular}

Fonte: os autores

Contudo, o problema a ser analisado no presente trabalho baseia-se em identificar quais foram as justificativas para os maiores cortes de vendas do período analisado (um ano), que por sua vez, foram aqueles que mais tiveram participação no Índice de Não Atendimento e com base nas boas práticas de mercado, propor soluções para que a causa raiz não volte acontecer e consequentemente, ocorra uma melhora significativa no INA. E dessa forma, a empresa tenha melhorias no seu nível de serviço e tenha ainda mais participação no mercado, ganhando competitividade. 


\subsection{Coleta de dados}

A coleta dos dados que serão utilizados como inputs para análise do trabalho ocorrerá a partir da consulta realizada no banco de dados da empresa. Serão recolhidas informações referentes aos resultados do INA, número de cortes de vendas e as respectivas justificativas de cortes (motivos e submotivos), compreendidas entre janeiro de 2016 e dezembro de 2016, totalizando um ano ou 12 observações periódicas, num total de 130 SKUs, classificados entre 6 categorias. Os valores serão coletados de forma mensal e serão exibidos com está unidade na linha do tempo.

\subsection{Seleção dos produtos}

Após a coleta dos dados, será utilizada a metodologia $\mathrm{ABC}$ para a seleção dos produtos. Para tal, como estamos querendo analisar o impacto em relação ao nível de serviço, serão classificados com base no total de cortes do ano, ou seja, o quanto deixaram de vender dos respectivos itens no período analisado.

Os resultados são exibidos a seguir: 
Tabela 2 - Classificação ABC

\begin{tabular}{|c|c|c|c|c|c|}
\hline Produto & Categoria & $\begin{array}{c}\text { Total Anual de } \\
\text { Cortes de Vendas }\end{array}$ & Percentual & $\begin{array}{l}\text { Percentual } \\
\text { Acumulado }\end{array}$ & $\begin{array}{c}\text { Classificação } \\
\text { ABC }\end{array}$ \\
\hline 1 & Sabonetes & 6304 & $48,45 \%$ & $48,45 \%$ & $A$ \\
\hline 2 & Perfumaria & 1444 & $11,10 \%$ & $59,55 \%$ & $A$ \\
\hline 3 & Perfumaria & 1199 & $9,22 \%$ & $68,76 \%$ & $A$ \\
\hline 4 & Sabonetes & 979 & $7,52 \%$ & $76,29 \%$ & $A$ \\
\hline 5 & Perfumaria & 464 & $3,57 \%$ & $79,86 \%$ & A \\
\hline 6 & Maquiagens & 440 & $3,38 \%$ & $83,24 \%$ & B \\
\hline 7 & Perfumaria & 428 & $3,29 \%$ & $86,53 \%$ & B \\
\hline 8 & Perfumaria & 268 & $2,06 \%$ & $88,59 \%$ & B \\
\hline 9 & Maquiagens & 240 & $1,84 \%$ & $90,43 \%$ & B \\
\hline 10 & Perfumaria & 234 & $1,80 \%$ & $92,23 \%$ & B \\
\hline 11 & Sabonetes & 104 & $0,80 \%$ & $93,03 \%$ & B \\
\hline 12 & Hidratantes & 71 & $0,55 \%$ & $93,57 \%$ & B \\
\hline 13 & Hidratantes & 68 & $0,52 \%$ & $94,10 \%$ & B \\
\hline 14 & Não Cosméticos & 58 & $0,45 \%$ & $94,54 \%$ & B \\
\hline 15 & Sabonetes & 58 & $0,45 \%$ & $94,99 \%$ & B \\
\hline 16 & Maquiagens & 53 & $0,41 \%$ & $95,40 \%$ & $\mathrm{~B}$ \\
\hline 17 & Hidratantes & 45 & $0,35 \%$ & $95,74 \%$ & $\mathrm{C}$ \\
\hline 18 & Maquiagens & 41 & $0,32 \%$ & $96,06 \%$ & $\mathrm{C}$ \\
\hline 19 & Batons & 39 & $0,30 \%$ & $96,36 \%$ & $\mathrm{C}$ \\
\hline 20 & Hidratantes & 37 & $0,28 \%$ & $96,64 \%$ & $\mathrm{C}$ \\
\hline 21 & Batons & 29 & $0,22 \%$ & $96,86 \%$ & C \\
\hline 22 & Batons & 28 & $0,22 \%$ & $97,08 \%$ & $\mathrm{C}$ \\
\hline 23 & Maquiagens & 27 & $0,21 \%$ & $97,29 \%$ & C \\
\hline 24 & Sabonetes & 26 & $0,20 \%$ & $97,49 \%$ & $\mathrm{C}$ \\
\hline 25 & Batons & 25 & $0,19 \%$ & $97,68 \%$ & $\mathrm{C}$ \\
\hline 26 & Perfumaria & 24 & $0,18 \%$ & $97,86 \%$ & C \\
\hline 27 & Batons & 18 & $0,14 \%$ & $98,00 \%$ & $\mathrm{C}$ \\
\hline 28 & Batons & 18 & $0,14 \%$ & $98,14 \%$ & $\mathrm{C}$ \\
\hline 29 & Perfumaria & 17 & $0,13 \%$ & $98,27 \%$ & C \\
\hline 30 & Batons & 15 & $0,12 \%$ & $98,39 \%$ & C \\
\hline 31 & Batons & 14 & $0,11 \%$ & $98,49 \%$ & $\mathrm{C}$ \\
\hline 32 & Hidratantes & 10 & $0,08 \%$ & $98,57 \%$ & $\mathrm{C}$ \\
\hline 33 & Maquiagens & 8 & $0,06 \%$ & $98,63 \%$ & $\mathrm{C}$ \\
\hline 34 & Hidratantes & 7 & $0,05 \%$ & $98,69 \%$ & $\mathrm{C}$ \\
\hline 35 & Hidratantes & 7 & $0,05 \%$ & $98,74 \%$ & C \\
\hline 36 & Perfumaria & 7 & $0,05 \%$ & $98,79 \%$ & C \\
\hline 37 & Sabonetes & 7 & $0,05 \%$ & $98,85 \%$ & $\mathrm{C}$ \\
\hline 38 & Maquiagens & 6 & $0,05 \%$ & $98,89 \%$ & C \\
\hline 39 & Maquiagens & 6 & $0,05 \%$ & $98,94 \%$ & C \\
\hline 40 & Hidratantes & 5 & $0,04 \%$ & $98,98 \%$ & $\mathrm{C}$ \\
\hline 41 & Hidratantes & 5 & $0,04 \%$ & $99,02 \%$ & $\mathrm{C}$ \\
\hline 42 & Não Cosméticos & 5 & $0,04 \%$ & $99,05 \%$ & $\mathrm{C}$ \\
\hline 43 & Sabonetes & 5 & $0,04 \%$ & $99,09 \%$ & $\mathrm{C}$ \\
\hline 44 & Maquiagens & 4 & $0,03 \%$ & $99,12 \%$ & $\mathrm{C}$ \\
\hline 45 & Hidratantes & 4 & $0,03 \%$ & $99,15 \%$ & $\mathrm{C}$ \\
\hline 46 & Não Cosméticos & 4 & $0,03 \%$ & $99,19 \%$ & $\mathrm{C}$ \\
\hline
\end{tabular}




\begin{tabular}{|c|c|c|c|c|c|}
\hline 47 & Batons & 3 & $0,02 \%$ & $99,21 \%$ & C \\
\hline 48 & Maquiagens & 3 & $0,02 \%$ & $99,23 \%$ & $\mathrm{C}$ \\
\hline 49 & Hidratantes & 3 & $0,02 \%$ & $99,25 \%$ & C \\
\hline 50 & Não Cosméticos & 3 & $0,02 \%$ & $99,28 \%$ & $\mathrm{C}$ \\
\hline 51 & Não Cosméticos & 3 & $0,02 \%$ & $99,30 \%$ & C \\
\hline 52 & Perfumaria & 3 & $0,02 \%$ & $99,32 \%$ & $\mathrm{C}$ \\
\hline 53 & Sabonetes & 3 & $0,02 \%$ & $99,35 \%$ & $\mathrm{C}$ \\
\hline 54 & Maquiagens & 2 & $0,02 \%$ & $99,36 \%$ & $\mathrm{C}$ \\
\hline 55 & Maquiagens & 2 & $0,02 \%$ & $99,38 \%$ & $\mathrm{C}$ \\
\hline 56 & Hidratantes & 2 & $0,02 \%$ & $99,39 \%$ & $\mathrm{C}$ \\
\hline 57 & Hidratantes & 2 & $0,02 \%$ & $99,41 \%$ & $\mathrm{C}$ \\
\hline 58 & Hidratantes & 2 & $0,02 \%$ & $99,42 \%$ & $\mathrm{C}$ \\
\hline 59 & Perfumaria & 2 & $0,02 \%$ & $99,44 \%$ & $\mathrm{C}$ \\
\hline 60 & Perfumaria & 2 & $0,02 \%$ & $99,45 \%$ & C \\
\hline 61 & Perfumaria & 2 & $0,02 \%$ & $99,47 \%$ & C \\
\hline 62 & Batons & 1 & $0,01 \%$ & $99,48 \%$ & $\mathrm{C}$ \\
\hline 63 & Batons & 1 & $0,01 \%$ & $99,49 \%$ & C \\
\hline 64 & Batons & 1 & $0,01 \%$ & $99,49 \%$ & $\mathrm{C}$ \\
\hline 65 & Batons & 1 & $0,01 \%$ & $99,50 \%$ & $\mathrm{C}$ \\
\hline 66 & Batons & 1 & $0,01 \%$ & $99,51 \%$ & $\mathrm{C}$ \\
\hline 67 & Batons & 1 & $0,01 \%$ & $99,52 \%$ & $\mathrm{C}$ \\
\hline 68 & Batons & 1 & $0,01 \%$ & $99,52 \%$ & C \\
\hline 69 & Batons & 1 & $0,01 \%$ & $99,53 \%$ & $\mathrm{C}$ \\
\hline 70 & Batons & 1 & $0,01 \%$ & $99,54 \%$ & $\mathrm{C}$ \\
\hline 71 & Batons & 1 & $0,01 \%$ & $99,55 \%$ & $\mathrm{C}$ \\
\hline 72 & Batons & 1 & $0,01 \%$ & $99,55 \%$ & C \\
\hline 73 & Batons & 1 & $0,01 \%$ & $99,56 \%$ & $\mathrm{C}$ \\
\hline 74 & Maquiagens & 1 & $0,01 \%$ & $99,57 \%$ & C \\
\hline 75 & Maquiagens & 1 & $0,01 \%$ & $99,58 \%$ & $\mathrm{C}$ \\
\hline 76 & Maquiagens & 1 & $0,01 \%$ & $99,58 \%$ & $\mathrm{C}$ \\
\hline 77 & Maquiagens & 1 & $0,01 \%$ & $99,59 \%$ & $\mathrm{C}$ \\
\hline 78 & Maquiagens & 1 & $0,01 \%$ & $99,60 \%$ & $\mathrm{C}$ \\
\hline 79 & Maquiagens & 1 & $0,01 \%$ & $99,61 \%$ & $\mathrm{C}$ \\
\hline 80 & Maquiagens & 1 & $0,01 \%$ & $99,62 \%$ & $\mathrm{C}$ \\
\hline 81 & Maquiagens & 1 & $0,01 \%$ & $99,62 \%$ & $\mathrm{C}$ \\
\hline 82 & Maquiagens & 1 & $0,01 \%$ & $99,63 \%$ & C \\
\hline 83 & Maquiagens & 1 & $0,01 \%$ & $99,64 \%$ & $\mathrm{C}$ \\
\hline 84 & Maquiagens & 1 & $0,01 \%$ & $99,65 \%$ & C \\
\hline 85 & Maquiagens & 1 & $0,01 \%$ & $99,65 \%$ & C \\
\hline 86 & Maquiagens & 1 & $0,01 \%$ & $99,66 \%$ & C \\
\hline 87 & Maquiagens & 1 & $0,01 \%$ & $99,67 \%$ & C \\
\hline 88 & Maquiagens & 1 & $0,01 \%$ & $99,68 \%$ & $\mathrm{C}$ \\
\hline 89 & Maquiagens & 1 & $0,01 \%$ & $99,68 \%$ & C \\
\hline
\end{tabular}




\begin{tabular}{|c|c|c|c|c|c|}
\hline 90 & Maquiagens & 1 & $0,01 \%$ & $99,69 \%$ & C \\
\hline 91 & Maquiagens & 1 & $0,01 \%$ & $99,70 \%$ & C \\
\hline 92 & Hidratantes & 1 & $0,01 \%$ & $99,71 \%$ & C \\
\hline 93 & Hidratantes & 1 & $0,01 \%$ & $99,72 \%$ & C \\
\hline 94 & Hidratantes & 1 & $0,01 \%$ & $99,72 \%$ & C \\
\hline 95 & Hidratantes & 1 & $0,01 \%$ & $99,73 \%$ & $\mathrm{C}$ \\
\hline 96 & Hidratantes & 1 & $0,01 \%$ & $99,74 \%$ & C \\
\hline 97 & Hidratantes & 1 & $0,01 \%$ & $99,75 \%$ & C \\
\hline 98 & Não Cosméticos & 1 & $0,01 \%$ & $99,75 \%$ & C \\
\hline 99 & Não Cosméticos & 1 & $0,01 \%$ & $99,76 \%$ & C \\
\hline 100 & Não Cosméticos & 1 & $0,01 \%$ & $99,77 \%$ & $\mathrm{C}$ \\
\hline 101 & Não Cosméticos & 1 & $0,01 \%$ & $99,78 \%$ & C \\
\hline 102 & Não Cosméticos & 1 & $0,01 \%$ & $99,78 \%$ & $\mathrm{C}$ \\
\hline 103 & Perfumaria & 1 & $0,01 \%$ & $99,79 \%$ & $\mathrm{C}$ \\
\hline 104 & Perfumaria & 1 & $0,01 \%$ & $99,80 \%$ & $\mathrm{C}$ \\
\hline 105 & Perfumaria & 1 & $0,01 \%$ & $99,81 \%$ & C \\
\hline 106 & Perfumaria & 1 & $0,01 \%$ & $99,82 \%$ & C \\
\hline 107 & Perfumaria & 1 & $0,01 \%$ & $99,82 \%$ & C \\
\hline 108 & Perfumaria & 1 & $0,01 \%$ & $99,83 \%$ & C \\
\hline 109 & Perfumaria & 1 & $0,01 \%$ & $99,84 \%$ & $\mathrm{C}$ \\
\hline 110 & Perfumaria & 1 & $0,01 \%$ & $99,85 \%$ & C \\
\hline 111 & Perfumaria & 1 & $0,01 \%$ & $99,85 \%$ & C \\
\hline 112 & Perfumaria & 1 & $0,01 \%$ & $99,86 \%$ & C \\
\hline 113 & Perfumaria & 1 & $0,01 \%$ & $99,87 \%$ & C \\
\hline 114 & Sabonetes & 1 & $0,01 \%$ & $99,88 \%$ & C \\
\hline 115 & Sabonetes & 1 & $0,01 \%$ & $99,88 \%$ & C \\
\hline 116 & Sabonetes & 1 & $0,01 \%$ & $99,89 \%$ & C \\
\hline 117 & Sabonetes & 1 & $0,01 \%$ & $99,90 \%$ & C \\
\hline 118 & Sabonetes & 1 & $0,01 \%$ & $99,91 \%$ & C \\
\hline 119 & Sabonetes & 1 & $0,01 \%$ & $99,92 \%$ & C \\
\hline 120 & Sabonetes & 1 & $0,01 \%$ & $99,92 \%$ & C \\
\hline 121 & Sabonetes & 1 & $0,01 \%$ & $99,93 \%$ & C \\
\hline 122 & Sabonetes & 1 & $0,01 \%$ & $99,94 \%$ & C \\
\hline 123 & Sabonetes & 1 & $0,01 \%$ & $99,95 \%$ & C \\
\hline 124 & Sabonetes & 1 & $0,01 \%$ & $99,95 \%$ & C \\
\hline 125 & Sabonetes & 1 & $0,01 \%$ & $99,96 \%$ & C \\
\hline 126 & Sabonetes & 1 & $0,01 \%$ & $99,97 \%$ & C \\
\hline 127 & Sabonetes & 1 & $0,01 \%$ & $99,98 \%$ & C \\
\hline 128 & Sabonetes & 1 & $0,01 \%$ & $99,98 \%$ & C \\
\hline 129 & Sabonetes & 1 & $0,01 \%$ & $99,99 \%$ & C \\
\hline 130 & Sabonetes & 1 & $0,01 \%$ & $100,00 \%$ & $\mathrm{C}$ \\
\hline \multicolumn{2}{|r|}{ Total } & 13011 & $100 \%$ & - & - \\
\hline
\end{tabular}

Fonte: os autores

Dessa forma, conseguimos chegar na seguinte análise: 
Figura 5 - Pareto: Classificação de Produtos

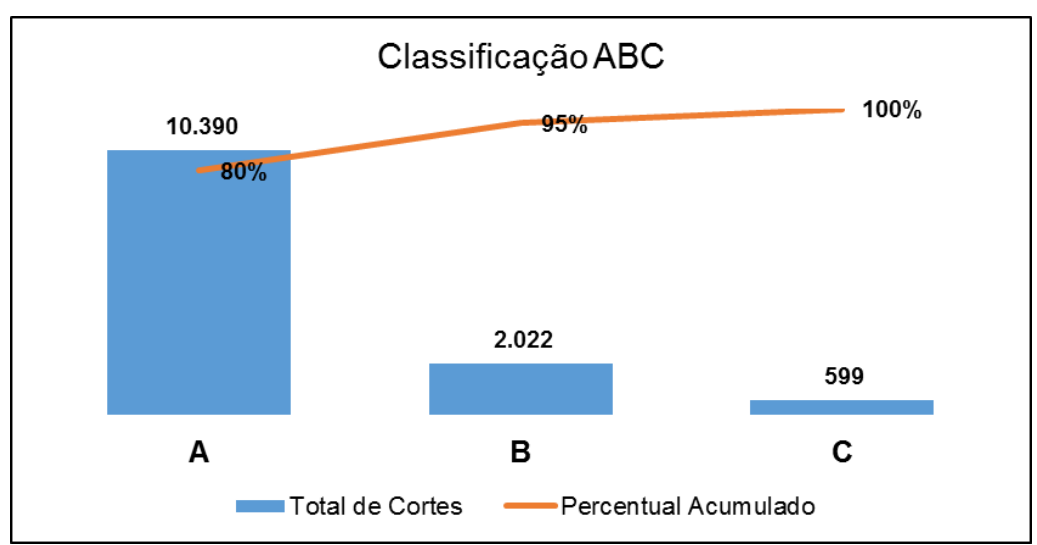

Fonte: os autores

De acordo com os resultados, do total anual de 13.011 cortes, 5 produtos representaram $80 \%$ (10.390 cortes), 11 produtos representaram $15 \%$ (2.022 cortes) e 114 produtos representaram $5 \%$ (599 cortes).

Dessa forma, selecionamos os itens classificados como A para serem analisados por terem maior representatividade em relação ao volume total de venda perdida.

Os produtos classificados como A, estão distribuídos em 2 categorias de produtos: 2 como "Sabonetes" e 3 como "Perfumaria".

A seguir temos as quantidades de cortes para cada um desses produtos, por mês para entendermos como variou o não atendimento durante o período.

Figura 6 - Quantidade de cortes por produto

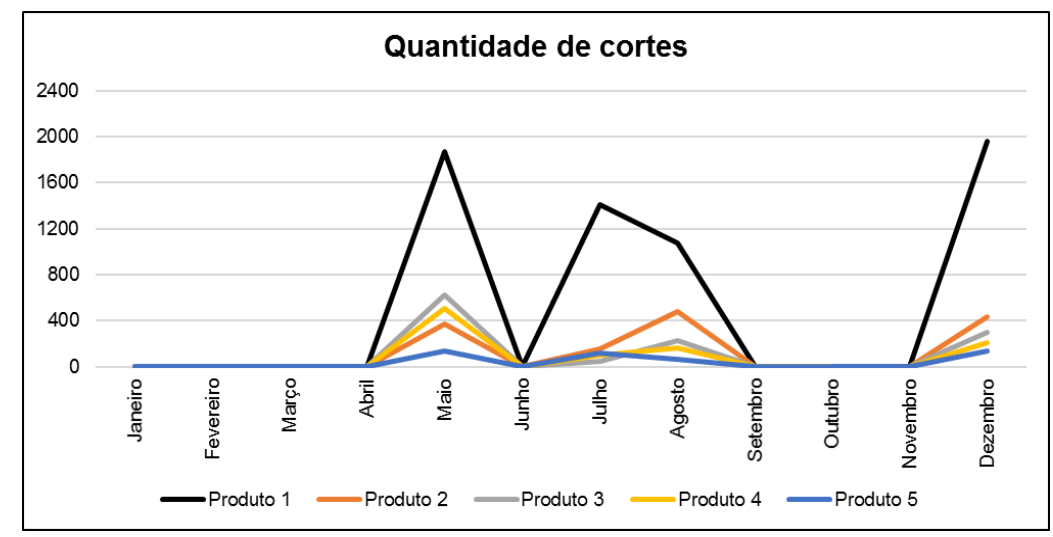

Fonte: os autores 
Com base nas curvas apresentada, podemos verificar que os cortes ocorreram em períodos específicos e que nestes períodos, existem algumas datas comemorativas, como dia das mães (maio), dia nos namorados (julho), dia dos pais (agosto) e natal (dezembro), seguindo uma certa sazonalidade. Normalmente, nestas datas, a demanda sempre é impulsionada com ações de vendas, o que nos permite pressupor que os cortes ocorreram devido a variação de demanda.

Para confirmar a hipótese acima, será analisado a seguir qual foi o INA gerado, a comparação entre o que foi previsto vender e o real vendido e qual a justificativa para o não atendimento para os meses que tiveram cortes.

\subsection{Análise de dados}

A "Quantidade de cortes" nos mostra que o produto 1 foi aquele que teve o maior número de cortes entre os analisados. A seguir temos o resultado do INA para os meses que os cortes se fizeram presentes, comparando o que era previsto se vender com aquilo que realmente foi vendido para todos os produtos:

- PRODUTO 1:

Figura 7 - Previsto x Realizado - Produto 1

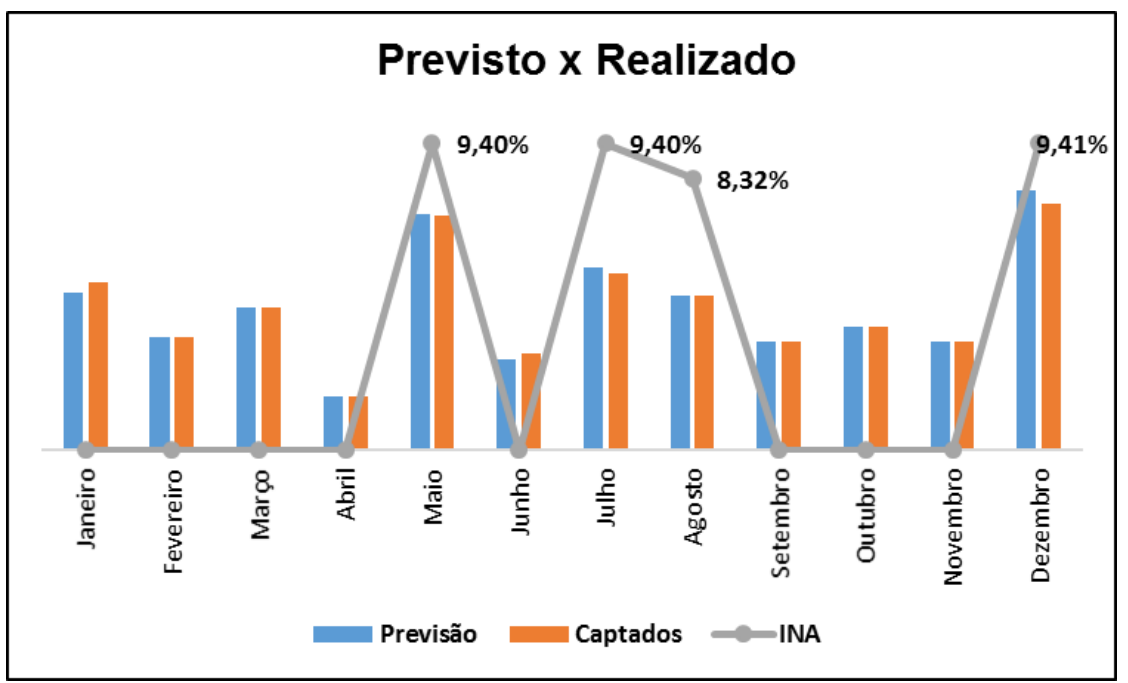

Fonte: os autores 
Podemos ver que para o produto 1, tivemos uma pequena diferença entre o que foi previsto e o real captado nos meses de maio, julho, agosto e dezembro, gerando um INA de 9,4\%, 9,4\%, $8,3 \%$ e $9,4 \%$, respectivamente para cada mês.

Tabela 3 - Dados Comparativos - Produto 1

\begin{tabular}{|c|c|c|c|c|c|}
\hline \multicolumn{6}{|c|}{ Produto 1} \\
\hline 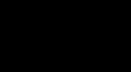 & Previsão & $\begin{array}{c}\text { Venda } \\
\text { Potencial }\end{array}$ & Captados & Cortes & INA \\
\hline Janeiro & 12098 & 12879 & 12879 & 0 & $0,00 \%$ \\
\hline Fevereiro & 8674 & 8674 & 8674 & 0 & $0,00 \%$ \\
\hline Março & 10934 & 10934 & 10934 & 0 & $0,00 \%$ \\
\hline Abril & 4185 & 4185 & 4185 & 0 & $0,00 \%$ \\
\hline Maio & 18087 & 19837 & 17972 & 1865 & $9,40 \%$ \\
\hline Junho & 7009 & 7469 & 7469 & 0 & $0,00 \%$ \\
\hline Julho & 13976 & 14976 & 13569 & 1407 & $9,40 \%$ \\
\hline Agosto & 11875 & 12874 & 11803 & 1071 & $8,32 \%$ \\
\hline Setembro & 8369 & 8369 & 8369 & 0 & $0,00 \%$ \\
\hline Outubro & 9483 & 9483 & 9483 & 0 & $0,00 \%$ \\
\hline Novembro & 8372 & 8372 & 8372 & 0 & $0,00 \%$ \\
\hline Dezembro & 19875 & 20847 & 18886 & 1961 & $9,41 \%$ \\
\hline
\end{tabular}

Fonte: os autores

Para esses meses em específico os submotivos apresentados foram: atraso na entrega da fábrica (maio, julho e agosto) e o lead time da cadeia de abastecimento para materiais de embalagem (dezembro).

Tabela 4 - Justificativas de cortes - Produto 1

\begin{tabular}{|l|l|l|}
$\begin{array}{l}\text { Periodo do } \\
\text { corte }\end{array}$ & \multicolumn{2}{|c|}{ Mustificativa } \\
\hline Maio & Superação de Vendas & Atraso na entrega da fábrica \\
\hline Julho & Superação de Vendas & Atraso na entrega da fábrica \\
\hline Agosto & Superação de Vendas & Atraso na entrega da fábrica \\
\hline Dezembro & Superação de Vendas & Lead time da cadeia de abastecimento - ME \\
\hline
\end{tabular}

Fonte: os autores 
- PRODUTO 2:

Figura 8 - Previsto x Realizado - Produto 2

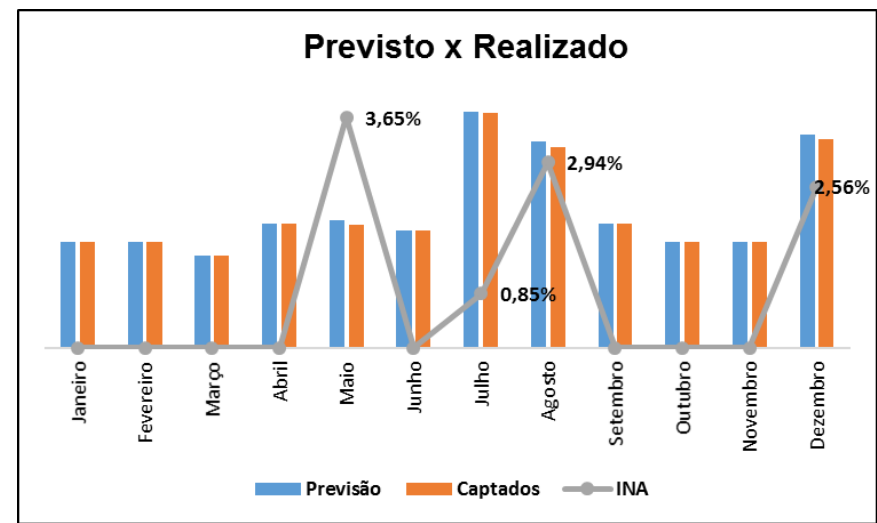

Fonte: os autores

Podemos ver que para o produto 2, tivemos uma pequena diferença entre o que foi previsto e o real captado nos meses de maio, julho, agosto e dezembro, gerando um INA de 3,6\%, 0,8\%, $2,9 \%$ e $2,5 \%$, respectivamente para cada mês.

Tabela 5 - Dados Comparativos - Produto 2

\begin{tabular}{c|c|c|c|c|c}
\hline \multicolumn{7}{|c}{ Produto 2 } \\
\hline & Previsão & $\begin{array}{c}\text { Venda } \\
\text { Potencial }\end{array}$ & Captados & Cortes & INA \\
\hline Janeiro & 8376 & 8376 & 8376 & 0 & $0,00 \%$ \\
\hline Fevereiro & 8374 & 8374 & 8374 & 0 & $0,00 \%$ \\
\hline Março & 7263 & 7263 & 7263 & 0 & $0,00 \%$ \\
\hline Abril & 9830 & 9830 & 9830 & 0 & $0,00 \%$ \\
\hline Maio & 10100 & 10297 & 9731 & 369 & $3,65 \%$ \\
\hline Junho & 9327 & 9489 & 9327 & 0 & $0,00 \%$ \\
\hline Julho & 18765 & 18708 & 18605 & 160 & $0,85 \%$ \\
\hline Agosto & 16393 & 16393 & 15911 & 482 & $2,94 \%$ \\
\hline Setembro & 9794 & 9794 & 9794 & 0 & $0,00 \%$ \\
\hline Outubro & 8373 & 8373 & 8373 & 0 & $0,00 \%$ \\
\hline Novembro & 8372 & 8372 & 8372 & 0 & $0,00 \%$ \\
\hline Dezembro & 16947 & 19877 & 16514 & 433 & $2,56 \%$ \\
\hline
\end{tabular}

Fonte: os autores

Para esses meses em específico os submotivos apresentados foram: atraso na entrega de terceiristas (maio, julho e dezembro). 
Tabela 6 - Justificativas de cortes - Produto

\begin{tabular}{|c|c|c|}
\hline \multicolumn{3}{|r|}{ Justificativa } \\
\hline $\begin{array}{c}\text { Período do } \\
\text { corte }\end{array}$ & Motivo & Submotivo \\
\hline Maio & Superação de Vendas & Atraso na entrega de terceiristas \\
\hline Julho & Superação de Vendas & Atraso na entrega de terceiristas \\
\hline Agosto & Superação de Vendas & Atraso na entrega de terceiristas \\
\hline Dezembro & Superação de Vendas & Atraso na entrega de terceiristas \\
\hline
\end{tabular}

Fonte: os autores

- PRODUTO 3:

Figura 9 - Previsto x Realizado - Produto 3

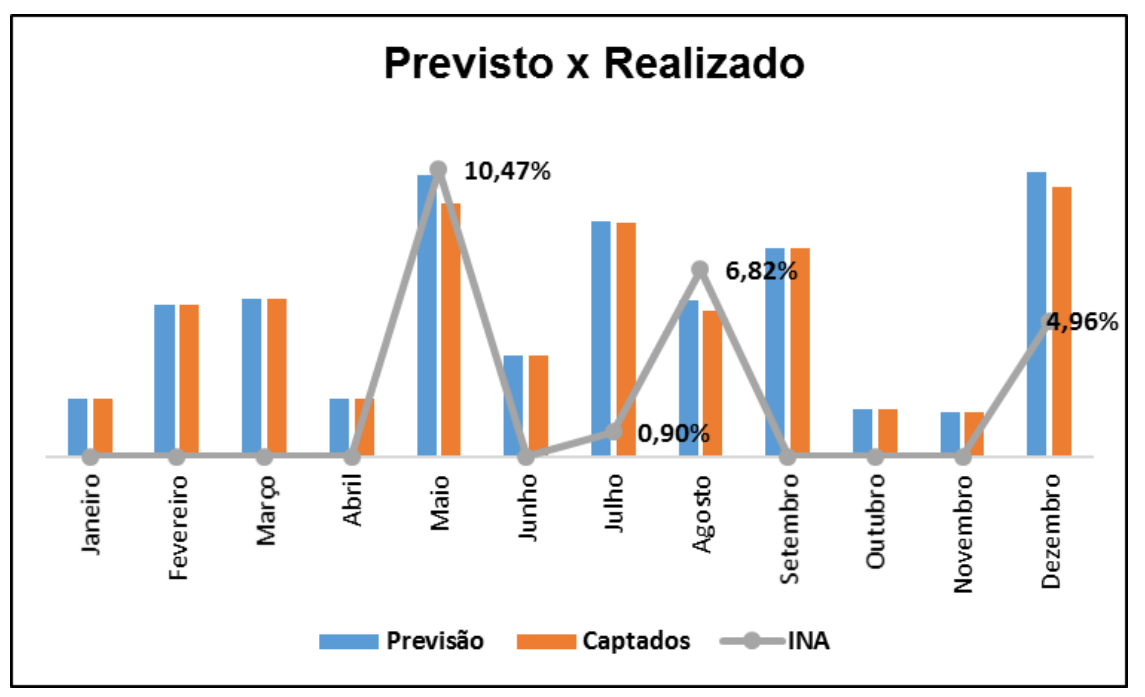

Fonte: os autores

Podemos ver que para o produto 3, tivemos uma pequena diferença entre o que foi previsto e o real captado nos meses de maio, julho, agosto e dezembro, gerando um ina de $10,4 \%, 0,9 \%, 6,8 \%$ e $4,9 \%$, respectivamente para cada mês. 
Tabela 7 - Dados Comparativos - Produto 3

\begin{tabular}{c|c|c|c|c|c}
\hline \multicolumn{7}{|c}{ Produto 3 } \\
\hline & Previsão & $\begin{array}{c}\text { Venda } \\
\text { Potencial }\end{array}$ & Captados & Cortes & INA \\
\hline Janeiro & 1233 & 1233 & 1233 & 0 & $0,00 \%$ \\
\hline Fevereiro & 3213 & 3213 & 3213 & 0 & $0,00 \%$ \\
\hline Março & 3341 & 3341 & 3341 & 0 & $0,00 \%$ \\
\hline Abril & 1234 & 1234 & 1234 & 0 & $0,00 \%$ \\
\hline Maio & 6000 & 6790 & 5372 & 628 & $10,47 \%$ \\
\hline Junho & 2134 & 2134 & 2134 & 0 & $0,00 \%$ \\
\hline Julho & 5005 & 5444 & 4960 & 45 & $0,90 \%$ \\
\hline Agosto & 3330 & 4321 & 3103 & 227 & $6,82 \%$ \\
\hline Setembro & 4434 & 4434 & 4434 & 0 & $0,00 \%$ \\
\hline Outubro & 1002 & 2322 & 1002 & 0 & $0,00 \%$ \\
\hline Novembro & 928 & 928 & 928 & 0 & $0,00 \%$ \\
\hline Dezembro & 6034 & 7393 & 5735 & 299 & $4,96 \%$ \\
\hline
\end{tabular}

Fonte: os autores

Para esses meses em específico os submotivos apresentados foram: atraso na entrega de terceiristas (maio, julho e dezembro).

Tabela 8 - Justificativa de cortes - Produto 3

\begin{tabular}{|c|c|c|}
\hline \multicolumn{3}{|r|}{ Justificativa } \\
\hline $\begin{array}{l}\text { Período do } \\
\text { corte }\end{array}$ & Motivo & Submotivo \\
\hline Maio & Superação de Vendas & Atraso na entrega de terceiristas \\
\hline Julho & Superação de Vendas & Atraso na entrega de terceiristas \\
\hline Agosto & Superação de Vendas & Atraso na entrega de terceiristas \\
\hline Dezembro & Superação de Vendas & Atraso na entrega de terceiristas \\
\hline
\end{tabular}

Fonte: os autores

- PRODUTO 4:

Figura 10 - Previsto x Realizado - Produto 4

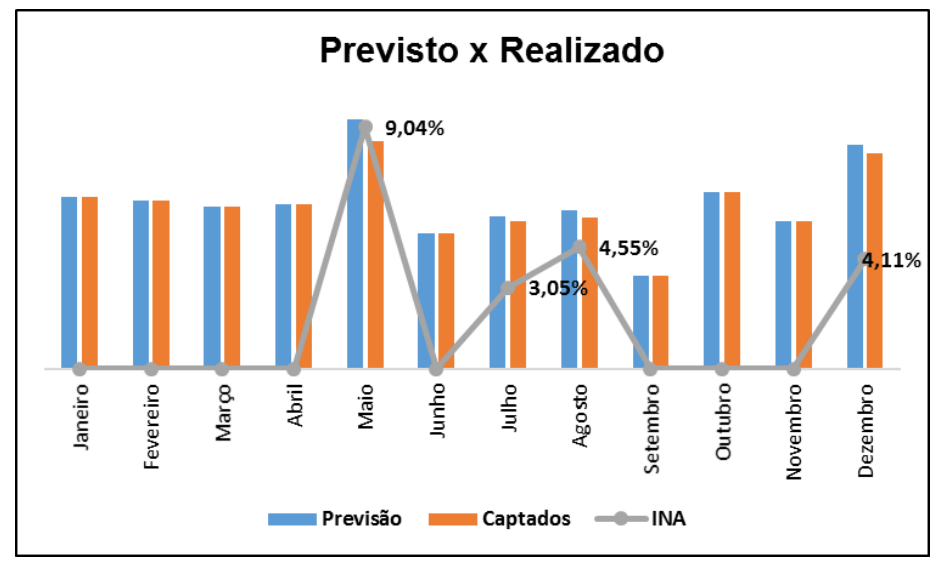

Fonte: os autores 
Podemos ver que para o produto 4 , tivemos uma pequena diferença entre o que foi previsto e o real captado nos meses de maio, julho, agosto e dezembro, gerando um ina de $9,0 \%, 3,0 \%, 4,5 \%$ e $4,1 \%$, respectivamente para cada mês.

Tabela 9 - Dados comparativos - Produto 4

\begin{tabular}{c|c|c|c|c|c}
\hline \multicolumn{7}{c}{ Produto 4 } \\
\hline & Previsão & $\begin{array}{c}\text { Venda } \\
\text { Potencial }\end{array}$ & Captados & Cortes & INA \\
\hline Janeiro & 3856 & 3856 & 3856 & 0 & $0,00 \%$ \\
\hline Fevereiro & 3779 & 3779 & 3779 & 0 & $0,00 \%$ \\
\hline Março & 3642 & 3642 & 3642 & 0 & $0,00 \%$ \\
\hline Abril & 3686 & 3686 & 3686 & 0 & $0,00 \%$ \\
\hline Maio & 5600 & 5947 & 5094 & 506 & $9,04 \%$ \\
\hline Junho & 3046 & 3046 & 3046 & 0 & $0,00 \%$ \\
\hline Julho & 3414 & 3414 & 3310 & 104 & $3,05 \%$ \\
\hline Agosto & 3561 & 3561 & 3399 & 162 & $4,55 \%$ \\
\hline Setembro & 2096 & 2096 & 2096 & 0 & $0,00 \%$ \\
\hline Outubro & 3974 & 3974 & 3974 & 0 & $0,00 \%$ \\
\hline Novembro & 3325 & 3325 & 3325 & 0 & $0,00 \%$ \\
\hline Dezembro & 5038 & 5038 & 4831 & 207 & $4,11 \%$ \\
\hline
\end{tabular}

Fonte: os autores

Para esses meses em específico os submotivos apresentados foram: Gargalo no recebimento do $\mathrm{CD}$ (maio), atraso na entrega da fábrica (julho), atendimento LATAM (agosto) e priorização por superação (dezembro).

Tabela 10 - Justificativas de cortes - Produto 4

\begin{tabular}{|l|l|l|}
\hline \multicolumn{3}{|c|}{ Justificativa } \\
\hline $\begin{array}{c}\text { Período do } \\
\text { corte }\end{array}$ & \multicolumn{1}{|c|}{ Motivo } & \multicolumn{1}{c|}{ Submotivo } \\
\hline Maio & Distribuição de estoques & Gargalo no recebimento do CD \\
\hline Julho & Superação de Vendas & Atraso na entrega da fábrica \\
\hline Agosto & Planejamento da Produção & Atendimento LATAM \\
\hline Dezembro & Planejamento da Produção & Priorização por Superação \\
\hline
\end{tabular}

Fonte: os autores 
Figura 11 - Previsto x Realizado - Produto 5

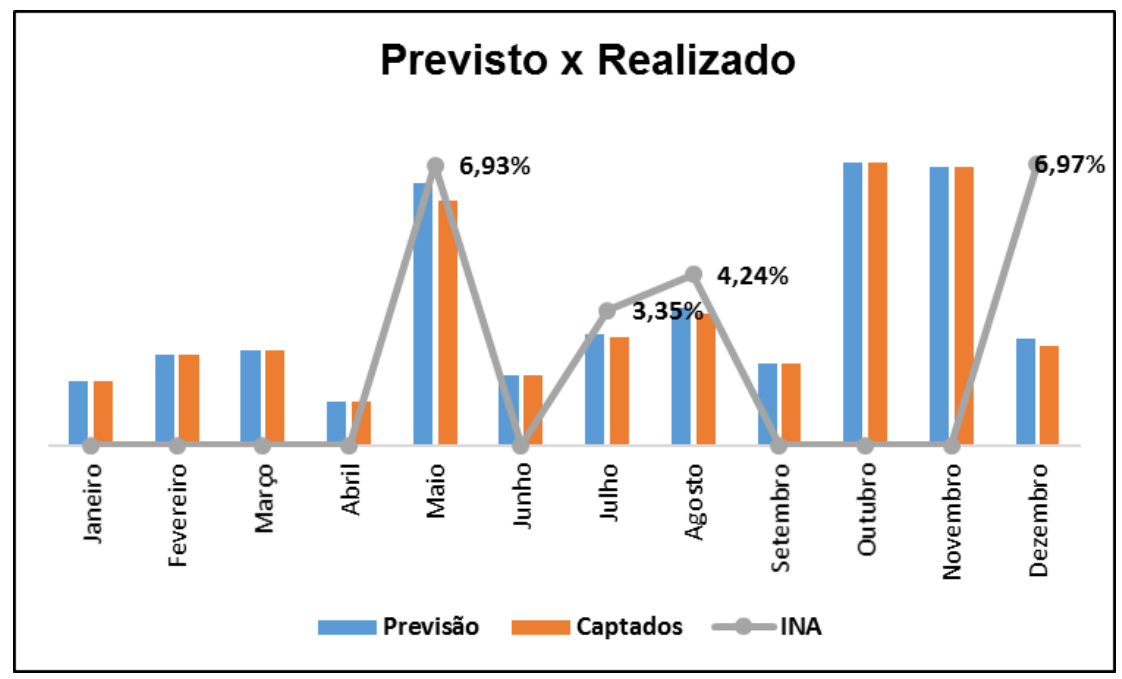

Fonte: os autores

Podemos ver que para o produto 5, tivemos uma pequena diferença entre o que foi previsto e o real captado nos meses de maio, julho, agosto e dezembro, gerando um ina de $6,9 \%, 3,3 \%, 4,2 \%$ e $6,9 \%$, respectivamente para cada mês.

Tabela 11 - Dados comparativos - Produto 5

\begin{tabular}{c|c|c|c|c|c}
\hline \multicolumn{7}{|c}{ Produto 5} \\
\hline & Previsão & $\begin{array}{c}\text { Venda } \\
\text { Potencial }\end{array}$ & Captados & Cortes & INA \\
\hline Janeiro & 1798 & 1928 & 1798 & 0 & $0,00 \%$ \\
\hline Fevereiro & 2516 & 438 & 2516 & 0 & $0,00 \%$ \\
\hline Março & 2646 & 208 & 2646 & 0 & $0,00 \%$ \\
\hline Abril & 1220 & 398 & 1220 & 0 & $0,00 \%$ \\
\hline Maio & 7300 & 7893 & 6794 & 506 & $6,93 \%$ \\
\hline Junho & 1931 & 873 & 1931 & 0 & $0,00 \%$ \\
\hline Julho & 3107 & 4839 & 3003 & 104 & $3,35 \%$ \\
\hline Agosto & 3825 & 4957 & 3663 & 162 & $4,24 \%$ \\
\hline Setembro & 2291 & 271 & 2291 & 0 & $0,00 \%$ \\
\hline Outubro & 7879 & 219 & 7879 & 0 & $0,00 \%$ \\
\hline Novembro & 7754 & 190 & 7754 & 0 & $0,00 \%$ \\
\hline Dezembro & 2970 & 6574 & 2763 & 207 & $6,97 \%$ \\
\hline
\end{tabular}

Fonte: os autores 
Para esses meses em específico os submotivos apresentados foram: Atraso na entrega de terceiristas (maio, julho, agosto e dezembro).

Tabela 12 - Justificativa de cortes - Produto 5

\begin{tabular}{|l|l|l|}
\hline \multicolumn{3}{|c|}{ Justificativa } \\
\hline $\begin{array}{l}\text { Período do } \\
\text { corte }\end{array}$ & \multicolumn{1}{|c|}{ Motivo } & \multicolumn{1}{c|}{ Submotivo } \\
\hline Maio & Superação de Vendas & Atraso na entrega de terceiristas \\
\hline Julho & Superação de Vendas & Atraso na entrega de terceiristas \\
\hline Agosto & Superação de Vendas & Atraso na entrega de terceiristas \\
\hline Dezembro & Superação de Vendas & Atraso na entrega de terceiristas \\
\hline
\end{tabular}

Fonte: os autores

\section{RESULTADOS ENCONTRADOS}

De acordo com a análise de dados, podemos notar que durante o ano, ocorreram cortes de vendas em 4 meses (maio, julho, agosto e dezembro) para os 5 produtos analisados, ou seja, tivemos um total de 20 justificativas de cortes, conforme podemos na tabela a seguir.

Tabela 13 - Total de justificativas de cortes

\begin{tabular}{|c|c|c|c|}
\hline \multicolumn{4}{|c|}{ Justificativa } \\
\hline Produto & \begin{tabular}{|c|}
$\begin{array}{c}\text { Período do } \\
\text { corte }\end{array}$ \\
\end{tabular} & Motivo & Submotivo \\
\hline \multirow{4}{*}{1} & Maio & Superação de Vendas & Atraso na entrega da fábrica \\
\hline & Julho & Superação de Vendas & Atraso na entrega da fábrica \\
\hline & Agosto & Superação de Vendas & Atraso na entrega da fábrica \\
\hline & Dezembro & Superação de Vendas & Lead time da cadeia de abastecimento - ME \\
\hline \multirow{4}{*}{2} & Maio & Superação de Vendas & Atraso na entrega de terceiristas \\
\hline & Julho & Superação de Vendas & Atraso na entrega de terceiristas \\
\hline & Agosto & Superação de Vendas & Atraso na entrega de terceiristas \\
\hline & Dezembro & Superação de Vendas & Atraso na entrega de terceiristas \\
\hline \multirow{4}{*}{3} & Maio & Superação de Vendas & Atraso na entrega de terceiristas \\
\hline & Julho & Superação de Vendas & Atraso na entrega de terceiristas \\
\hline & Agosto & Superação de Vendas & Atraso na entrega de terceiristas \\
\hline & Dezembro & Superação de Vendas & Atraso na entrega de terceiristas \\
\hline \multirow{4}{*}{4} & Maio & Distribuição de estoques & Gargalo no recebimento do $C D$ \\
\hline & Julho & Superação de Vendas & Atraso na entrega da fábrica \\
\hline & Agosto & Planejamento da Produção & Atendimento LATAM \\
\hline & Dezembro & Planejamento da Produção & Priorização por Superação \\
\hline \multirow{4}{*}{5} & Maio & Superação de Vendas & Atraso na entrega de terceiristas \\
\hline & Julho & Superação de Vendas & Atraso na entrega de terceiristas \\
\hline & Agosto & Superação de Vendas & Atraso na entrega de terceiristas \\
\hline & Dezembro & Superação de Vendas & Atraso na entrega de terceiristas \\
\hline
\end{tabular}

Fonte: os autores 
Podemos notar que dentre os motivos apresentados anteriormente que das 20 justificativas que foram dadas, 17 (cerca de 85\%) delas tiveram como motivo a "Superação de Vendas", 2 (cerca de 10\%) tiveram como motivo o "Planejamento da Produção" e 1 (cerca de 5\%) teve com motivo a 'Distribuição de estoques". Ou seja, a hipótese de ter ocorrido um aumento de demanda, puxada pelas datas comemorativas é verdadeira.

Indo um pouco mais afundo, tivemos como principal submotivo o "Atraso na entrega de terceiristas" em 13 casos (cerca de 65\%), seguido por "Atraso na entrega da fábrica" com ocorrência de 3 vezes (cerca de 15\%). As demais justificativas, tiveram como submotivo o "Lead time da cadeia de fornecimento - ME" (Cerca de 5\%), o "Gargalo no recebimento do CD” (Cerca de 5\%), “Atendimento LATAM" (Cerca de 5\%) e "Priorização por Superação" (Cerca de 5\%).

Tabela 14 - Justificativa de cortes - Ocorrências

\begin{tabular}{c|c|l|c}
\hline Motivos & \% de ocorrências & \multicolumn{1}{|c|}{ Submotivos } & \% de ocorrências \\
\hline \multirow{2}{*}{ Superação de Vendas } & \multirow{2}{*}{$85 \%$} & Atraso na entrega de terceiristas & $65 \%$ \\
\cline { 3 - 4 } & & Atraso na entrega da fábrica & $15 \%$ \\
\hline \multirow{2}{*}{ Planejamento da Produção } & \multirow{2}{*}{$10 \%$} & Lead time da cadeia de abastecimento - ME & $5 \%$ \\
\cline { 3 - 4 } & & Gargalo no recebimento do CD & $5 \%$ \\
\hline \multirow{2}{*}{ Distribuição de estoques } & \multirow{2}{*}{$5 \%$} & Atendimento LATAM & $5 \%$ \\
\cline { 3 - 4 } & & Priorização por Superação & $5 \%$ \\
\hline
\end{tabular}

Fonte: os autores

\section{REFERÊECIAS}

BALLOU, Ronald H.; Gerenciamento da Cadeia de Suprimentos/Logística Empresarial.

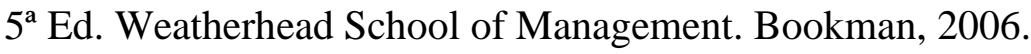

BENDER, P. How to design na optimum worldwide supply chain. Supply Chain Management Review, Massachusetts, v. 1, Spring 1997.

CARROL, Lewis. Alice's Adventures in Wonderland. New York: 1983, 1983. Pág 72.

CHRISTOPHER, M. Logística e Gerenciamento da Cadeia de Suprimentos: estratégias para redução dos custos e melhoria dos serviços. São Paulo: Pioneira, 1997.

FARIA, A. C.; COSTA, M. F. G. Gestão de custos logísticos: custeio baseado em atividades (ABC), balanced scorecard (BSC), valor econômico agregado (EVA). São Paulo: Atlas, 2008. 
KYJ, L. S. AND KYJ, M. J. "Customer Service Differentiation in International Markets", International Journal of Physical Distribution \& Logisttics Management. Vol. 24, p. 3. 1994.

LENZA, E. Desenvolvimento sustentável e lucratividade como fatores de contribuição para sobrevivência das organizações: uma abordagem a partir da análise do relatório anual da empresa Natura Cosméticos S.A, 2008.

William Copacino and Donald B. Rosenfield, "Analytic Tools for Strategic Planning”, International Journal of Physical DIstribution and Materials Management, vol. 15, $\mathrm{n}^{\mathrm{o}} 3$ (1985), pág 48. 